\title{
Os 40 anos da ginástica aeróbica: Das aulas clássicas ao surgimento do fitDance
}

\author{
40 years of aerobic gymnastics: From classic classes to the emergence of fitDance \\ 40 años de gimnasia aeróbica: De las clases clásicas a la aparición del fitDance
}

Recebido: 22/06/2021 | Revisado: 29/06/2021 | Aceito: 04/07/2021 | Publicado: 07/07/2021

\author{
Francisca Synára Soares Medeiros \\ ORCID: https://orcid.org/0000-0002-2373-5750 \\ Centro Universitário Santo Agostinho,Brasil \\ E-mail: synarastb2010@gmail.com \\ Joysce Karolynne Moreira Lima de Sousa \\ ORCID: https://orcid.org/0000-0001-6630-4021 \\ Centro Universitário Santo Agostinho,Brasil \\ E-mail: joyscekarolynne09@gmail.com \\ Kácio dos Santos Silva \\ ORCID: https://orcid.org/0000-0003-1577-0270 \\ Centro Universitário Santo Agostinho,Brasil \\ Universidade Estadual do Piauí,Brasil \\ E-mail: kaciosantos@ frn.uespi.br
}

\begin{abstract}
Resumo
O presente estudo refere-se às transformações nas aulas de dança aeróbica ocorridas nos 40 anos da ginástica aeróbica no Brasil. A ginástica aeróbica é caracterizada por movimentos rítmicos e intensos com elevado gasto calórico pois, exige bastante da pessoa e gera impacto sobre as articulações, deixando a pessoa mais saudável a partir do momento em que ela começa a se exercitar e criar movimentos. Esta pesquisa teve como objetivo analisar a evolução das aulas de ginástica de academia e suas mais expressivas mudanças. Como metodologia serão incluídos no estudo materiais que revelem os diferentes tipos de modalidade aeróbicas de acordo com cada época sejam eles artigos, sites, matérias, ou outros documentos. Através dos resultados analisados verificou-se que a ginástica foi se modificando com o passar dos anos, influenciado por movimentos culturais e musicais de acordo com algumas épocas. Dessa forma, a ginástica pode ser facilmente transformada em segura, descomplicada e recompensadora por tudo e, ainda, conservar o elemento que causa "emoção" - aquela estimulação cinestésica que imediatamente leva os alunos a quererem mais. A pesquisa revelou que desde quando surgiu no Brasil, a ginástica aeróbica passou por diferentes períodos que influenciaram suas diversas metodologias e depois vai se modificando, com a inserção de músicas latinas e brasileiras, a exemplo da lambaeróbica, das aulas da Bodysistems, da zumba e mais recentemente o fitDance.
\end{abstract}

Palavras-chave: Ginástica aeróbica; Dança aeróbica; FitDance.

\begin{abstract}
The present study refers to the transformations in aerobic dance classes that took place in the 40 years of aerobic gymnastics in Brazil. Aerobic gymnastics is characterized by rhythmic and intense movements with high caloric expenditure because it demands a lot from the person and impacts the joints, leaving the person healthier from the moment he starts exercising and creating movements. This research aimed to analyze the evolution of gym classes in the gym and its most expressive changes. As a methodology, materials will be included in the study that reveal the different types of aerobic modality according to each period, whether articles, websites, materials, or other documents. Through the analyzed results, it was verified that gymnastics was changing over the years, influenced by cultural and musical movements according to some periods. In this way, gymnastics can be easily transformed into safe, uncomplicated and rewarding for everything, and still retain the element that causes "emotion" - that kinesthetic stimulation that immediately leads students to want more. The research revealed that since its emergence in Brazil, aerobic gymnastics has gone through different periods that influenced its various methodologies and then changes, with the inclusion of Latin and Brazilian music, such as lambaeróbica, Bodysistems, zumba and most recently fitDance.
\end{abstract}

Keyword: Aerobics; Aerobic dance; FitDance.

\section{Resumen}

El presente estudio se refiere a las transformaciones en las clases de danza aeróbica ocurridas en los 40 años de gimnasia aeróbica en Brasil. La gimnasia aeróbica se caracteriza por realizar movimientos rítmicos e intensos con alto gasto calórico porque exige mucho a la persona y genera un impacto en las articulaciones, dejando a la persona más sana desde el momento en que comienza a ejercitarse y creando movimientos. Esta investigación tuvo como objetivo analizar la evolución de las clases de gimnasia en el gimnasio y sus cambios más expresivos. Como metodología, se incluirán en el estudio materiales que revelen los diferentes tipos de modalidad aeróbica según cada período, ya sean 
artículos, sitios web, materiales u otros documentos. A través de los resultados analizados, se constató que la gimnasia fue cambiando a lo largo de los años, influenciada por movimientos culturales y musicales según algunas épocas. De esta manera, la gimnasia se puede transformar fácilmente en segura, sin complicaciones y gratificante para todo, y aún así conservar el elemento que causa la "emoción", esa estimulación cinestésica que inmediatamente lleva a los estudiantes a querer más. La investigación reveló que desde su aparición en Brasil, la gimnasia aeróbica ha pasado por diferentes períodos que influyeron en sus diversas metodologías y luego cambios, con la inclusión de la música latina y brasileña, como lambaeróbica, Bodysistems, zumba y más recientemente fitDance.

Palabras clave: Gimnasia aeróbica; Danza aeróbica; FitDance.

\section{Introdução}

Chama-se ginástica aeróbica as atividades físicas caracterizadas por movimentos rítmicos e intensos com elevado gasto calórico pois, exige bastante da pessoa e gera impacto sobre as articulaçõesdeixando a pessoa mais saudável a partir do momento em que ela começa a se exercitar e criar movimentosquase sempre acompanhados de música, e que produzem um aumento metabólico e uso de substratos benéficos ao organismo, onde os adeptos, em todas as idades e de todas as formas, buscam entender melhor o próprio corpo, os riscos que correm, os mecanismos para o desenvolvimento de uma vida saudável (Barbantini, 1991).

A Ginástica em Academia foi influenciada por alguns métodos estrangeiros, que contribuíram e sofreram alterações até chegarmos no modelo atual. Nas décadas de 60 e 70,foi a Calistenia; na de 80,a Ginástica Aeróbica(alto e baixo Impacto),nos anos 90, pelo Step Training e a Ginástica Localizada, que tem sua base na musculação (Moura et al.,2007).

Uma das modalidades que também influenciou a evolução da ginástica foi a utilização de ritmos e danças. ParaMenoti (2006),a dança faz parte das manifestações humanas desde a Idade da Pedra,comprovada pelas gravuras desenhadas no interior das cavernas que mostram as atividades cotidianas dos homens dessa época, como exemplo, a pesca, a caça, a alimentação, os ritos de vida, de morte, de casamento, entre outros. Para Nanni (2008), A dança como arte conceitual, portanto, é forma de comunicação e expressão, é uma das manifestações inerentes à natureza do homem, presentes nos acontecimentos de sua vida: nascimento e morte, guerra e paz, celebrações e rituais. Ela estabelece íntima relação com as emoções e sentimentos humanos; antecede como forma de comunicação à própria linguagem falada, característica hoje tão escassa ao homem contemporâneo.

Nesse sentido, a dança influencia várias formas de fazer ginástica. Um exemplo de modalidade que ganhou força nas academias de ginástica no século XXI foi a Zumba. Conforme o Instructor training Manual publicado em 2010, essa modalidade de exercício físico proveniente do desenvolvimento da ginástica aeróbica,se configura como uma mescla entre ginástica e dança, utilizando músicas latinas e internacionais. Após a ginástica aeróbica, o programa Zumba Fitness surgiu com o objetivo de aliar ritmos latinos com movimentos da própria ginástica durante as aulas. A modalidade surgiu na Colômbia, em 1991, quando Alberto Perez esqueceu os CDs para sua aula de aeróbica, e teve que improvisar com CDs de música latina que trazia em seu carro.

Para Moreira(2016), diante da aceitação e comercialização de novas modalidades,empresas começaram a desenvolver programas de aulas direcionados para o público fitness. Nesses tipos de programas, o professor precisa realizar um curso para receber certificação e se tornar apto para dar aula da modalidade específica.

Atualmente, uma das danças coreografadas presentes na academia está o FitDance. Os fundadores desse programa, o definem como um estilo de vida e acreditam que os participantes se movimentam, dançam ativando o corpo e a mente, além de elevar o bem-estar. De acordo com seus idealizadores, esse é o principal objetivo, propiciar alegria e diversão em todos os momentos da vida das pessoas, seja em casa, no trabalho, no celular, em reuniões com os amigos, nas academias ou nas festas (Duarte, 2016).

O programa utiliza uma proposta inclusiva, a FitDance, trabalha com movimentos coreográficos modernos pensados de forma didática, proporcionando o aprendizado e a evolução do praticante, contemplando todos os estilos musicais. A grande 
repercussão obtida, pela atividade, tem como pilar a unidade das coreografias, que promove a integração e faz com que todos dancem juntos (Duarte, 2016).

O FitDance é um programa de dança e diversão que se propõe a tornar a vida das pessoas mais divertida por meio da dança.É uma aula coletiva que tem como objetivo promover uma participação e presença assídua de seus praticantes. O sucesso se deve basicamente aos seus pilares, os 5D's, conforme apresentados abaixo: Dança, porque acima de tudo é um programa de dança.Diversão,porque prezam pelo bem-estar e a alegria.Dinâmico,porque sempre se atualizam com novos hits e estilos musicais, acabando não caindo na monotonia. Democrático, porque é inclusivo e didático, para melhor assimilação. Com todos os estilos musicais,todo mundo que quer ser feliz pode participar.Desafiador, porque as coreografias são mescladas com passos básicos, simples e outros mais elaborados, além de um cuidado na limpeza das contagens e movimentos, causando assim um maior desafio e desenvolvimento da coordenação motora do praticante.Sendo assim,esse novo programa de dança coreografada que está presente nas plataformas digitais, como Youtube, Instagram, Spotify, de maneira geral na internet, vem conquistando um grande público que se mostra presente em seus eventos e projetos (Duarte,2016).

Neste sentido, esta pesquisa teve como objetivo analisar a evolução das aulas de ginástica de academia e suas mais expressivas mudanças.

\section{Metodologia}

Este estudo é uma revisão de literatura integrativa de abordagem qualitativa e do tipo bibliográfica e documental seguindo uma organização historiográfica. De acordo com Gil (2002, p.62-3), a pesquisa documental apresenta algumas vantagens por ser "fonte rica e estável de dados": não implica altos custos, não exige contato com os sujeitos da pesquisa e possibilita uma leitura aprofundada das fontes. Segundo Gil (1999), a pesquisa documental é muito semelhante à pesquisa bibliográfica.A diferença essencial entre ambas está na natureza das fontes: enquanto a bibliográfica se utiliza fundamentalmente das contribuições de diversos autores, a documental vale-se de materiais que não receberam, ainda, um tratamento analítico, podendo ser reelaboradas de acordo com os objetos dapesquisa.

ParaOliveira(2007)a pesquisa bibliográfica é uma modalidade de estudo e análise de documentos de domínio científico tais como livros, periódicos, enciclopédias, ensaios críticos, dicionários e artigos científicos que busca proporcionar aos pesquisadores o contato direto com obras, artigos ou documentos que tratem do tema em estudo. Já a pesquisa documental caracteriza-se pela busca de informações em documentos que não receberam nenhum tratamento científico, como relatórios, reportagens de jornais, revistas, cartas, filmes, gravações, fotografias, entre outras matérias dedivulgação.

Para a pesquisa, utilizou-se as seguintes bases de dados: livros, artigos científicos disponíveis nas plataformas eletrônicas SciELO e Google acadêmico, além de matérias de revistas midiáticas que foram encontradas na plataforma Google. Para tanto, utilizou-se as seguintes palavras-chave "Ginástica aeróbica", "Dança aeróbica" e "Fitdance" e o operador boleano AND. Posteriormente estabeleceu-se os critérios de inclusão e exclusão de artigos e matérias, em seguida a definição das informações que seriam retiradas dos estudos selecionados, bem como a avaliação dos estudos, a interpretação e apresentação dos resultados.

Foram incluídos na pesquisa: artigos científicos indexados nestes bancos de dados, artigos completos, disponíveis online.Os critérios de inclusão para seleção dos artigos foram: matérias,sites,revistas e artigos que tratam sobre o tema ginástica aeróbica e fitdance, artigos publicados no período compreendido entre 2000 a 2021; e artigos publicados em língua portuguesa. A exclusão ocorreu em artigos que não apresentaram dados sobre ginástica aeróbica e fitDance, bem como artigos repetidos, incompletos ou que fugiam do temaproposto.

A princípio, encontrou-se cerca de 130 títulos relacionados com os descritores na base acadêmica, no entanto, tais resultado refletiam também documentos publicados fora do período considerado pela pesquisa e em outra língua que não o 
português,alguns artigos foram descartados pelo fato de serem antigos,data anterior a 2000.Dos artigos e matérias encontrados, 6 estudos revelaram-se correlacionados atendendo a todos os descritores e objetivos. Através destas etapas foi possível categorizar modalidades de acordo com cada década.

\section{Resultados e Discussão}

A presente pesquisa revelou desde o surgimento da ginástica aeróbica na década de 1980, vários outros movimentos surgiram influenciados por épocas. No Quadro 1, podemos perceber algumas das modalidades que mais foram popularizadas.

Quadro 1. Modalidades de ginástica aeróbica de acordo com décadas.

\begin{tabular}{|c|c|c|c|}
\hline DÉCADA & $\begin{array}{l}\text { ESTILO DE } \\
\text { GINÁSTICA }\end{array}$ & DESCRIÇÃO & FONTE \\
\hline \multirow[t]{2}{*}{1980} & Ginástica aeróbica & $\begin{array}{l}\text { A ginástica aeróbica é uma modalidade em que os ginastas executam } \\
\text { movimentos aeróbicos muito difíceis, que consistem na interpretação da } \\
\text { música que acompanha o exercício, caracterizada pelo ritmo acelerado, } \\
\text { tal como os utilizados nas academias. }\end{array}$ & $\begin{array}{l}\text { https://www.efdeportes.co } \\
\text { m/efd175/ginastica- } \\
\text { aerobica-como- } \\
\text { ferramenta-de- } \\
\text { interlocucao.htm }\end{array}$ \\
\hline & Lambaeróbica & $\begin{array}{l}\text { A lambaeróbica mistura os passos da lambada com movimentos típicos } \\
\text { das aulas de aeróbica, atividade que melhora a capacidade cardíaca e a } \\
\text { resistência físico- respiratória. Com muita ginga e diversão, os treinos } \\
\text { de lambaeróbica queimam calorias e estresse na mesma intensidade. E } \\
\text { seguem atraindo adeptos no Brasil e no mundo, sobretudo devido à } \\
\text { versatilidade de ritmos e benefícios para o corpo. }\end{array}$ & https://bityli.com/Apxdc \\
\hline \multirow[t]{2}{*}{1990} & Body systems & $\begin{array}{l}\text { Body Systems, consistiam em atividadespré-coreografadas com uma } \\
\text { grande variedade de modalidades: Body Balance (inspirada na ioga, tai } \\
\text { chi e pilates), BodyPump (mescla de movimentos de ginástica com } \\
\text { peso), BodyCombat (reprodução de movimentos de luta), BodyStep } \\
\text { (atividade com o uso do step), Body Jam (movimentos de dança) e RPM } \\
\text { (aula de ciclismoindoor). }\end{array}$ & https://bityli.com/9CTJJ \\
\hline & Eurodance & $\begin{array}{l}\text { EurodanceécaracterizadopeloTechnoinstrumental,vocais femininos, } \\
\text { refrões simples, raps com vocais masculinos, simplese uma batida bem } \\
\text { forte que varia na maioria das vezes entre } 110 \text { e } 150 \text { BPM (batidas por } \\
\text { minuto) com riffs feitos através de sintetizadores. O som é bem positivo, } \\
\text { sempre acompanhado de letras que envolvem temas como amor, festa e } \\
\text { paz, sempre dançantes eexpressando } \\
\text { emoções. }\end{array}$ & $\begin{array}{l}\text { http://historymusic95.blog } \\
\text { spot.com/2013/01/a- } \\
\text { historia-da- } \\
\text { eurodance.html?m=1 }\end{array}$ \\
\hline 2000 & Zumba & $\begin{array}{l}\text { O programa de Zumba é o exercício mais eficaz, mais inovador, e } \\
\text { emocionante projetado para todos, é um programa de aulas onde a } \\
\text { música Latina é o carro chefe e que, juntamente com passos de dança, } \\
\text { criam uma dinâmica excitante e eficaz para que tudo vire uma festa! }\end{array}$ & $\begin{array}{l}\text { https://revistaatencao.com. } \\
\text { br/danca-e-saude-aulas- } \\
\text { de-zumba-com-aline-ar/ }\end{array}$ \\
\hline
\end{tabular}




\begin{tabular}{|c|c|c|c|}
\hline 2010 & Fitdance & $\begin{array}{l}\text { O FitDance vai muito além de uma vídeo aula de dança. É algo que traz } \\
\text { um prazer enorme, não só por proporcionar exercício físico, mas por } \\
\text { sentir aquela alegria única que só quem aprendeu a coreografia de seu } \\
\text { artista favorito sabe! Atualmente há cerca de } 15 \text { mil academias adotando } \\
\text { o seu método divertido no Brasil e na Argentina, sem contar os mais de } \\
10 \text { milhões de seguidores em cinco canais voltados para diferentes } \\
\text { públicos, como FitDanceKidseTeen, FitDance Life eFitDanceSwag. }\end{array}$ & $\begin{array}{l}\text { https://festivalteen.com.br/ } \\
\text { conheca-a-historia-por- } \\
\text { tras-do-sucesso-do- } \\
\text { fitdance.html }\end{array}$ \\
\hline
\end{tabular}

Fonte: Medeiros e Sousa (2021).

No Quadro 1, observou-se que a ginástica foi se modificando com o passar dos anos, influenciado por movimentos culturais e musicais de acordo com algumas épocas. Para Russel (1980, p.11) a ginástica pode ser facilmente transformada em segura, descomplicada e recompensadora por tudo e, ainda, conservar o elemento que causa "emoção" - aquela estimulação cinestésica que imediatamente leva os alunos a quererem mais.“A origem da dança aeróbica,ou ginástica aeróbica é atribuídaa Jacki Sorenses em 1969.A ginástica aeróbica tem como objetivo controle de peso,convívio social,expressão estética,satisfação da prática e motivação vinda da música (Valim; Volp,1998).

No entanto, esta modalidade teve expansão pelo mundo por meio da influência de personalidades famosas, como Sydney Rome e Jane Fonda, que produziram vídeos dos programas de dança e exercícios que passaram a fazer parte da mídia." (Araujo, 2017, p. 05). Um dos movimentos de ginástica surgido na década de 1980 foi a lambaeróbica, considerada à época uma das melhores opções para quem estava entrando na academia e que teve muita continuidade na década de 1990.Para Filho, (1998) neste período surge “o mundo fitness" para satisfazer uma maior demanda de alunos, que buscavam a ginástica de academia. Surgiram então as novas modalidades: aeroolodum, aerobrasil, aerofunk, lambaeróbica, step, steplocal, localizada e alongamento, entre outros.

De acordo com o Quadro 1, no final dos anos 90, a Body Systems chega ao Brasil com suas aulas pré-coreografadas ou aulas prontas, provocando um impacto significativo no mercado.Body Systems foram programas de aula bastante procuradas pelo fato de serem eficientes e motivadoras, já que o trabalho em conjunto proporciona uma energia que domina todas as salas de aula.Para Furtado, (2009) o programa de aula Body Systems envolve várias modalidades, com aulas précoreografadas ou aulasprontas.SegundoFlores (2015),essas modalidades são releituras da ssessões da ginástica tradicional,conhecidas tais como step, localizada e dança aeróbica.

Na sequência do Quadro 1, a Eurodance se revela entre os anos de 1992 a 1995, sendo Alemanha e Itália onde se mais produziu eurodance. Alguns produtores que mais se destacaram nesse tipo de gênero foi o sueco Max Martine o italiano Larry Pignagnoli. Fica também, evidenciado que a zumba é um programa de ginástica com dança que engloba vários ritmos latinos e internacionais como salsa, merengue, cumbia e reggaeton, os passos são básicos e simples para que as pessoas se divirtam e percam calorias com facilidade, os movimentos não precisam ser executados com tanta precisão, mas devem seguir os movimentos do professor e sempre manter uma boa postura. A mudança de ritmos provoca uma mudança na frequência cardíaca que proporciona uma experiência em vários níveis de intensidade sem pausa, trazendo também benefícios como: melhora na autoestima e no relacionamento interpessoal,aumento da disposição e estabilidade emocional. Algumas pesquisas investigaram os efeitos agudos das aulas de Zumba, entre eles, o gasto calórico (Luettgen et al.2012).

Com isso, a Zumba se torna um treino completo para o indivíduo de forma mais livre e descontraída, sem sepreocupar se os movimentos são executados com perfeição, mesmo se seguindo uma coreografia organizada "não existe conotação de passos certos e errados, o importante é continuar os movimentos do corpo e a diversão, não existem erros, só solos inesperados" assim,todos podem seguir a coreografia.Contudo,é importante ressaltar que se o movimento for executado de 
maneira incorreta pode ocasionar, com o tempo, lesões e cabe ao profissional os corrigir (Zumba,2010).

Para Sartor e Bom (2015) a Zumba é uma modalidade de exercício físico proveniente do desenvolvimento da ginástica aeróbica e se constitui como uma mistura de dança com ginástica, que incorpora músicas latinas e internacionais. A as músicas latinas com os movimentos fáceis e repetitivos, a Zumba vem atraindo até o público da terceira idade. Segundo Alves (2016), uma aula de 20 minutos de Zumba ${ }^{\circledR}$ fitness, reduziu 20\% do estado de ansiedade das voluntárias. Para Hass e Garcia (2006), a dança como atividade física melhora a disposição para as atividades do dia-a-dia podendo proporcionar ao indivíduo que a pratica, força muscular, estética corporal e autoestima, através dos movimentos realizados pela atividade.

Na década de 2010, surgiu o fitdance criado em 2014 pelos irmãos e empresários Fabio Duarte e Bruno Duarte, a FitDance é um programa de aulas de dança que tem como propósito levar mais felicidade e saúde mental à vida das pessoas. Com quase 9 anos de existência, o canal que começou como um sonho, se tornou realidade! Com milhares de seguidores nas redes sociais e milhões de visualizações nos vídeos do YouTube, o FitDancetem como objetivo não deixar ninguém parado ao som de suas músicas e artistas prediletos.

O projeto traz uma metodologia dinâmica, divertida e até mesmo desafiadora para alguns, mas mais importante para o grupo é deixar todo mundo feliz! Atualmente há cerca de 15 mil academias adotando o seu método divertido no Brasil e na Argentina, sem contar os mais de 10 milhões de seguidores em cinco canais voltados para diferentes públicos,como FitDanceKids\&Teen,FitDance Life e FitDanceSwag, um projeto voltado para todas as modalidades e idades, onde buscam sempre oferecer as melhores coreografias. Fitdance ainda fornece cursos para se tornar trainner e instrutor fitdance apartir de cursos presenciais com testes para aprovar os alunos em uma das duas etapas,para que possam realizar aulas comamarca da empresa.

Para alcançaras pessoas dos mais diferentes estilos e idades, a FitDance aposta em seu repertório musical. Segundo Miranda e Godeli (2003), a música influencia o estado afetivo-emocional das pessoas; permite o indivíduo a desfrutar de sentimentos e sensações agradáveis. A música é inerente aoser humano,para cada situação ou momento o indivíduo terá alguma relação voltada a música, seja ela qual for.

\section{Conclusão}

A presente pesquisa revelou que desde quando surgiu no Brasil, a ginástica aeróbica passou por diferentes períodos que influenciaram suas diversas metodologias. Pode-se perceber que a ginástica aeróbica surge inicialmente influenciada pelo mercado estadunidense e depois vai se modificando,com a inserção de músicas latinas e brasileiras,a exemplo da lambaeróbica, das aulas da Bodysistems, da zumba e mais recentemente ofitDance.

Esta pesquisa teve a intenção de mapear como a ginástica aeróbica foi se modificando no decorrer dos seus 40 anos,no entanto é necessário destacar que durante este período surgiram muitas outras modalidades,onde algumas,por vezes,não tenham sido destaque nas academias, o que não a torna menos interessante e/ou importante. Dessa forma, foi possível destacar aquelas modalidades que tiveram maior destaque.

\section{Referências}

Alves, C. L. (2016)Efeito do exergame zumba fitness sobre o estado de ansiedade em mulheres jovens. Faculdade Educação Física e Dança da universidade federal de Goiás. Goiânia. Trabalho de finalização da disciplina de núcleo temático em pesquisa II (Bacharelado em Educação Física) Universidade Federal de Goiás.

Araújo.A. S. S (2017). Percepção da imagem corporal em servidoras da universidade federal doRio Grande do Norte- UFRN praticantes de Zumba. Monografia ( curso bacharelado . emeducação física) Universidade Federal do Rio Grande do, Centro de Ciências da Saúde.

Barbanti, V. (1991).Aptidão Física e Saúde. Revista da Fundação de Esporte e ,Curitiba, 3(1): 5-8,

Duarte, F. (2016). Manual FitDance N1.

Filho, C. A. A. (1998)O discurso do profissional de ginástica em academia no Rio de Janeiro. Gama, a. 
Research, Society and Development, v. 10, n. 8, e40910817446, 2021

(CC BY 4.0) | ISSN 2525-3409 | DOI: http://dx.doi.org/10.33448/rsd-v10i8.17446

Flores, A. A. (2015). Ginástica em Academia: compreensões sobre o planejamento de aulas em Salvador. Dissertação de mestrado.Salvador. https://repositorio.ufba.br/ri/bitstream/ri/18857/1/Disserta\%c3\%a7\%c3\%a3o\%20Amanda\%20Azevedo\%20Flores.pdf

Furtado, RP. (2009). Do fitness ao wellness: os três estágios de desenvolvimento das academias de ginástica. Pensar a Prática, 12(1), 12

Gil, A. C. (1999).Métodos e técnicas de pesquisa social. (5a ed.), Atlas.

Gil, A.C.(2002). Como elaborar projetos de pesquisa. 4 ed.), Editora Atlas S/A.

Hass, A. N.\& Garcia, A. (2006) Ritmo e dança. Canoas.Ed. ULBRA.

Luettgen, M. et al., (2012). Zumba(®): isthe "fitness-party" a goodworkout? Journalof Sports Science and Medicine11(2), 357-358.

Miranda, J. L. M., \& Godeli, C. R. M. (2003).Música, atividade física e bem-estar psicológico em idosos - Revista Brasileira de Ciência e Movimento. 11, 87$94-$ out $/$ dez.

Moura, N. L., et aL (2007) . A influência motivacional das músicas em mulheres praticantes de ginástica em academia.Revista Mackenzie de Educação Física e Esporte- 6 (3): 103-118

Menoti, J., \& Lima, M. (2016). Dança e as culturas juvenis nas aulas de educação física.Revista ColloquiumHumanarum, Presidente Prudente. 13, $28-32$.

Nanni, D. (2008). Dança- Educação - pré-escola à universidade. (5a ed.), Sprint.

Moreira, A. T. R. (2016). Aproximações ou distanciamentos com a dança a partir da concepção, objetivos e estrutura de aula de Zumba. Campina Grande.

Oliveira, M. M. (2007)Como fazer pesquisa qualitativa. Petrópolis, Vozes.

Russel, K. (1980). Gymnastics - whyis it in schoolcurricula. LeisureandMovement. JournaloftheSzskatchewanPhysicalEducationAss`. 6(1), 7-11.

Sartor, F., \& Bom, F.. (2015). Correlação entre a frequência cardíaca e a percepção subjetiva de esforço em aulas dezumba®. Trabalho de conclusão de curso- TCC (bacharelado em educação física) Universidade do Extremo Sul Catarinense, UNESC.

Volp, C. M., Deutsch, S., \& Schwartz, G. M. (1995).Por que dançar? Um estudo comparativo. Motriz. 1, 52-58.

Zumba. (2010). Instructor Training Manual: basicsstepslevel 1. Hollywood: Zumba® Fitness, LLC. 